\title{
PTMs in Conversation: Activity and Function of Deubiquitinating Enzymes Regulated via Post-Translational Modifications
}

\author{
Benedikt M. Kessler • Mariola J. Edelmann
}

Published online: 12 April 2011

(c) The Author(s) 2011. This article is published with open access at Springerlink.com

\begin{abstract}
Deubiquitinating enzymes (DUBs) constitute a diverse protein family and their impact on numerous biological and pathological processes has now been widely appreciated. Many DUB functions have to be tightly controlled within the cell, and this can be achieved in several ways, such as substrate-induced conformational changes, binding to adaptor proteins, proteolytic cleavage, and posttranslational modifications (PTMs). This review is focused on the role of PTMs including monoubiquitination, sumoylation, acetylation, and phosphorylation as characterized and putative regulative factors of DUB function. Although this aspect of DUB functionality has not been yet thoroughly studied, PTMs represent a versatile and reversible method of controlling the role of DUBs in biological processes. In several cases PTMs might constitute a feedback mechanism insuring proper functioning of the ubiquitin proteasome system and other DUB-related pathways.
\end{abstract}

Keywords Ubiquitin · Protease $\cdot$ Post-translational modification · Phosphorylation - Acetylation . Ubiquitination · Deubiquitination · Deubiquitinating enzymes

\section{B. M. Kessler}

Henry Wellcome Building for Molecular Physiology, Nuffield Department of Medicine, University of Oxford, Roosevelt Drive, Oxford OX3 7BN, UK

M. J. Edelmann ( $\square)$

Life Sciences \& Biotechnology Institute, Mississippi Agricultural and Forestry Experimental Station, Mississippi State University, Pace Seed Lab, Room 115, 650 Stone Blvd, Mississippi State, MS 39762, USA

e-mail:mje100@mafes.msstate.edu

\author{
Abbreviations \\ $\mathrm{UCH}$ Ubiquitin $C$-terminal hydrolase \\ USP Ubiquitin-specific protease \\ OTU Ovarian tumor domain \\ PTM Post-translational modification
}

\section{Introduction}

The human genome encodes for approximately 80 putative deubiquitinating enzymes (DUBs), including cysteine proteases and several metalloproteases [1]. The diverse functions that DUBs play within the cell can be classified into three major categories. Firstly, DUBs process linear polyubiquitin precursor proteins, such as ribosomal fusion proteins, into single ubiquitin molecules (reviewed in [2]). Secondly, DUBs recycle ubiquitin by processing polyubiquitin chains to generate free ubiquitin that can subsequently enter the ubiquitin pool for subsequent ubiquitin conjugation events. This is a critical process since free polyubiquitin chains can inhibit the binding of polyubiquitinated substrates to the $26 \mathrm{~S}$ proteasome competitively [3-5]. Finally, DUBs remove ubiquitin from ubiquitinated substrates, antagonizing ubiquitin conjugation by E3 ligases $[6,7]$. The vast number of DUBs belonging to five distinct protein families suggests that there is a specialization in terms of their function and specificity. Indeed, it has been demonstrated that DUBs target distinct pathways and their localization may be limited to certain subcellular compartments [1, 8]. Moreover, many DUBs have been linked to pathological conditions, underlying their physiological significance in health and disease (reviewed in [9]). 


\section{Modes of Regulation of DUB Activity}

Since the catalytic activity of DUBs is so specific and in many cases functionally critical, one would anticipate multiple mechanisms of its control, and several ones have been already described (reviewed in [10]). DUBs are generally expressed as active enzymes, rather than inactive precursors. However, certain DUBs require ubiquitin binding to obtain their active conformation and that prevents their uncontrolled proteolytic activity. The structural data for several DUBs reveal that ubiquitin-binding by DUBs is accompanied by active site rearrangements and that such conformational alterations induce their hydrolytic activity, which has been demonstrated for OTUB1, UCH-L1, UCH-L3, USP7, USP14, and S. cerevisiae YUH1 [11-19]. Another way of modulating DUB activity is through the binding of scaffold and adaptor proteins. Some DUBs display low affinity for ubiquitin and therefore require additional interactors for binding ubiquitinated substrates efficiently [20]. DUBs may require to be incorporated into large macromolecular complexes to attain the active state, exemplified by USP14 or POH1 that are activated by their binding to the $26 \mathrm{~S}$ proteasome complex [10, 21, 22]. Activation of USP8 and AMSH is facilitated by signal transducing adaptor molecule 2 (STAM2), and both proteins are involved in regulating endocytic trafficking [23]. Protein-protein interactions can also inhibit protease activity, for example UCH37 function is inhibited by its binding to the chromatin-remodeling complex [24]. Proteolytic cleavage of DUBs is another way of regulation of their function. This is exemplified by USP1, which undergoes autoproteolysis that in turn inactivates this enzyme [25]. Last but not least, many DUBs are subjected to post-translational modifications (PTMs), possibly representing an effective and reversible means of regulating their activity or function. This review will discuss the documented examples of the PTMs in DUBs and their various phenotypic consequences (summarized in Table 1).

\section{Phosphorylation of CYLD in the NF- $\kappa$ B Pathway}

The ubiquitin-specific protease involved in cylindromatosis (CYLD) is one of the best studied examples of posttranslationally modified DUBs. CYLD specifically cleaves Lys $^{63}$-linked polyubiquitin chains and acts on TRAF2, TRAF6, and several other substrates, which results in negative regulation of the NF- $\kappa \mathrm{B}$ pathway ([26-28], reviewed in [29]). CYLD is a tumor suppressor and an important player in the host defense mechanisms against bacterial infection, as shown for several pathogens [30-33]. CYLD becomes phosphorylated as a response to treatment with a number of NF- $\kappa$ B-inducing factors, such as LPS or TNF- $\alpha$ [34]. This transient modification occurs at several sites in a region located within close proximity to the TRAF2-binding site, which includes $\mathrm{Ser}^{418}$. The biochemical analysis using phosphomimetic mutants demonstrated that this PTM negatively affects the deubiquitinating activity of CYLD on TRAF2, most likely through interfering with the catalytic activity of CYLD, since the binding of TRAF2 to a CYLD mutant mimicking phosphorylation on $\mathrm{Ser}^{418}$ is not affected (Fig. 1a; [34]). There is some initial evidence that IKK $\gamma$ (I kappa B kinase gamma) mediates CYLD phosphorylation on $\operatorname{Ser}^{418}$ [34], although a more recent report suggests that IKK $\varepsilon$ (I kappa B kinase epsilon) is a much more efficient kinase for this site [35]. Interestingly, IKK $\alpha$ (I kappa B kinase alpha) and IKKß (I kappa B kinase beta) are also able to phosphorylate CYLD in vitro, although in vivo they require additional assistance of IKK $\gamma$. In addition to down-regulation of the NF- $\kappa$ B pathway [34], CYLD phosphorylation has been demonstrated to have a physiological relevance in increasing cell transformation [35], hence precise identification of a kinase or a kinase cascade involved in this process might provide potential targets for pharmacological intervention strategies in the treatment of cancer.

\section{Phosphorylation-Regulated Activity of A20}

A20 is an ovarian tumor domain (OTU)-containing protease with a well-defined function in pro-inflammatory events. It down-regulates activation of the transcription factor NF- $\kappa \mathrm{B}$ and therefore plays an important role in inflammation [36-38]. Interestingly, next to the OTU domain involved in cleavage of Lys ${ }^{63}$-linked polyubiquitin chains from the protein substrates TRAFs, RIPs and NEMO, it also contains the $C$-terminal zinc finger domain that acts as a ubiquitin ligase and is responsible for building $\mathrm{Lys}^{48}{ }^{4}$-linked polyubiquitin conjugates on RIPs, thus targeting them to the proteasome $[39,40]$. Therefore, A20 has a dual, or editing function on its substrates, removing one type of polyubiquitin chain and attaching another. A positional scanning peptide library technique combined with a bioinformatics approach identified A20 as a putative substrate for the IKKß kinase. Mass spectrometric analysis mapped the phosphorylation site to $\operatorname{Ser}^{381}$ that was verified in vitro and in vivo. IKKß-mediated A20 phosphorylation has been shown to increase its activity toward NEMO, thereby further down-regulating the NF- $\kappa \mathrm{B}$ pathway. It is not conclusive, however, whether phosphorylation on $\mathrm{Ser}^{381}$ affects the E3 ubiquitin ligase or deubiquitinase activity of A20, although the modification occurs at the zinc finger domain of the protein, so the former would be expected [41]. 


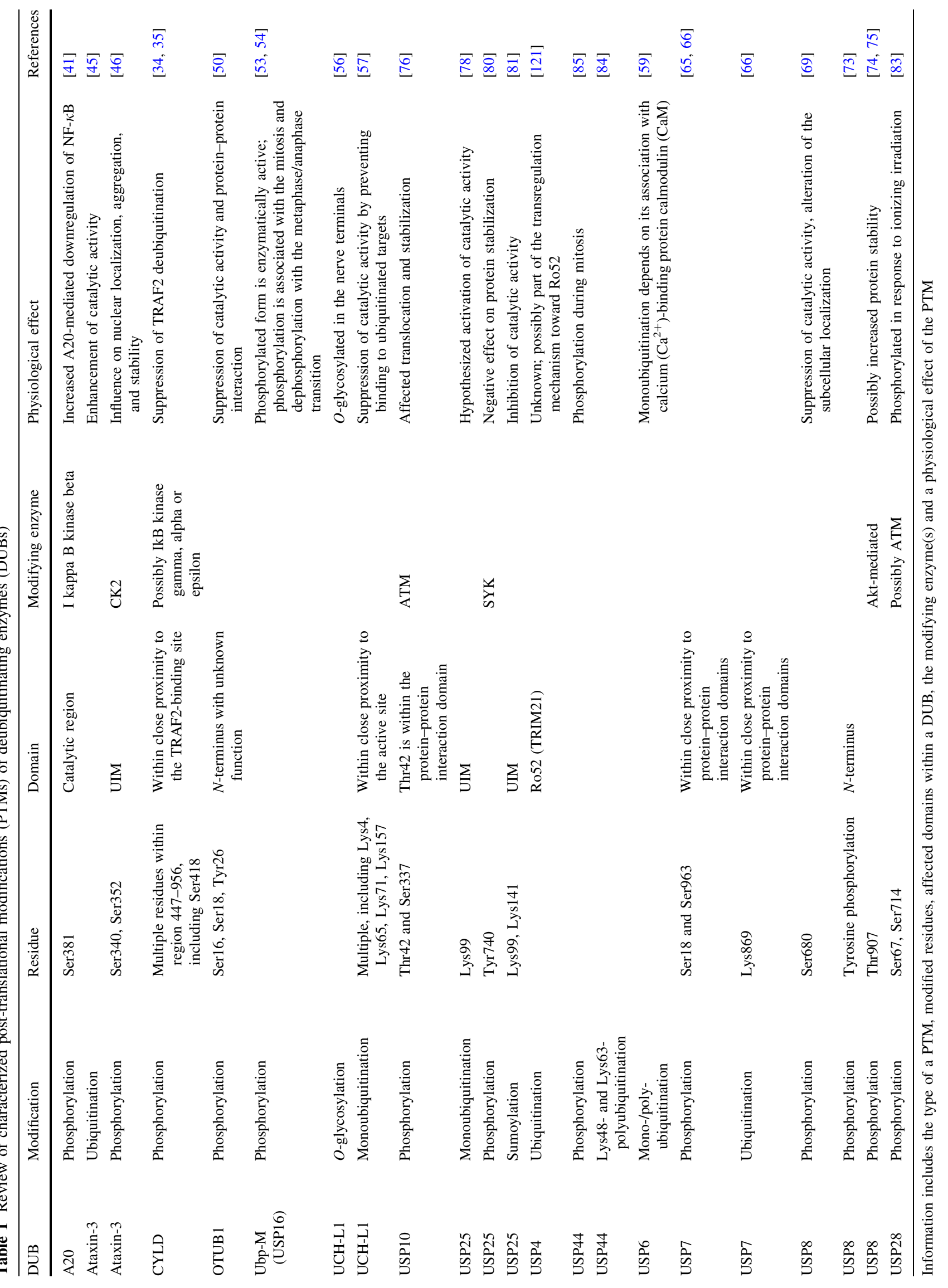



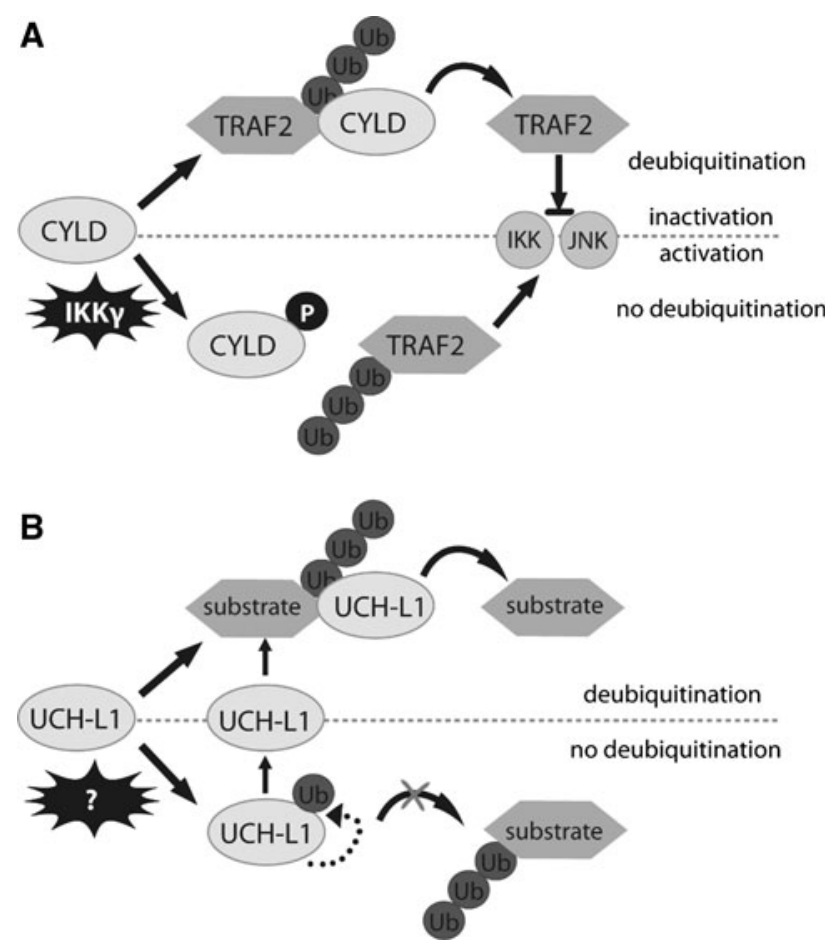

Fig. 1 PTMs in control of DUB activity exemplified by CYLD and UCH-L1. a Phosphorylation of CYLD impairs its deubiquitinating activity toward TRAF2. CYLD cleaves Lys ${ }^{63}$-linked polyubiquitin chains from TRAF2, which results in negative regulation of the NF- $\kappa$ B pathway by inactivation of kinases JNK and IKK. IKK $\gamma$ mediated phosphorylation impairs its catalytic activity, in effect contributing to activation of JNK and IKK and positive regulation of NF- $\kappa$ B. b Monoubiquitination of UCH-L1 modulates its enzymatic function. UCH-L1 shortens conjugated polyubiquitin chains on the substrate proteins, and monoubiquitination of $\mathrm{UCH}-\mathrm{L} 1$ hinders this activity by impairing its binding to ubiquitin. UCH-L1 is able to selfregulate its own ubiquitination status through auto-deubiquitination

\section{Post-Translational Modifications Modulate Function of Ataxin-3}

Ataxin-3 (AT3) is a polyglutamine disease protein regulating ERAD substrate trafficking to the proteasome. It contains an $N$-terminal Josephin domain [42] and preferentially cleaves Lys $^{63}$-polyubiquitin chains, displaying even higher activity toward Lys ${ }^{63}$-ubiquitin linkages that are within mixed linkage ubiquitin chains [43]. AT3 undergoes ubiquitination [44], which increases its ability to process hexa-ubiquitin chains but in the tested conditions it does not alter its specificity to the linkage type [45]. This observation has been made for both wild-type AT3 and the pathogenic AT3 with polyQ expansion causing a neurodegenerative disorder, spinocerebellar ataxia type 3/Machado-Joseph disease (SCA3/MJD). Ubiquitination of AT3 can be induced by certain stress factors, including inhibition of the proteasome or treatment with dithiothreitol (DTT) that promotes the unfolded protein response (UPR). It has therefore been proposed that AT3 is regulated by a feedback loop mechanism that helps to restore the homeostasis related to the ubiquitin pathway [45]. Moreover, AT3 is phosphorylated by protein casein kinase 2 (CK2). Phosphorylation occurs within the ubiquitin interacting motif (UIM) of AT3 and is critical for the nuclear localization of normal and pathogenic AT3. Inhibition of AT3 phosphorylation contributes to its decreased translocation to the nucleus and formation of nuclear inclusions. CK2-dependent phosphorylation of AT3 might be crucial in the stress response, because thermal stress has been shown to increase the CK2-modulated nuclear abundance of AT3. Furthermore, phosphorylation might also stabilize AT3, as observed in a pulse-chase experiment using an AT3 mutant mimicking phosphorylation [46].

\section{Otubain 1 Phosphorylation Interferes with its Catalytic Activity and Function in Bacterial Infection}

Otubain 1 (OTUB1), a member of OTU-containing protein family, is the only DUB for which specificity for Lys ${ }^{48}$ ubiquitin linkages has been clearly documented [12, 47]. OTUB1 functions in $T$ cell anergy [48, 49], infection with Yersinia [50] and in DNA double strand break repair [51]. OTUB 1 is predicted to have multiple phosphorylation sites, and three of them have been mapped to $\mathrm{Ser}^{16}$, $\mathrm{Ser}^{18}$, and $\mathrm{Tyr}^{26}$ [50]. Phosphomimicry analysis suggests that phosphorylation on these sites influences protein-protein binding and the ability of OTUB1 to react with a ubiquitinbased active-site probe, indicating reduction of its catalytic activity. OTUB1-mediated stabilization of a small GTPase RhoA involved in cytoskeletal alterations has been negatively regulated by phosphorylation, which might be either due to decreased protein-protein binding capabilities or a lower catalytic activity. Finally, the physiological relevance of this modification is highlighted by the fact that OTUB1 phosphomimetic mutants did not influence bacterial invasion, in contrast to the wildtype OTUB1 [50]. The phosphorylation sites are all located in the $N$-terminal part of OTUB1, a domain that has been shown to be critical to exert its function in regulating DNA double strand break repair, indicating a possible regulatory mechanism $[51,52]$.

\section{Ubp-M Phosphorylation on the Onset of Mitosis}

A novel ubiquitin-processing protease Ubp-M (USP16) has been recently identified in the pool of proteins phosphorylated during mitosis [53]. Its function is yet unknown, but it has been postulated that Ubp-M might interfere with cell viability by modifying chromatin functions. The fact that Ubp-M is capable of deubiquitinating histone $\mathrm{H} 2 \mathrm{~A}$ in vitro is consistent with this hypothesis. Interestingly, 
phosphorylation does not interfere with the enzymatic activity of this DUB, but it does correlate with histone $\mathrm{H} 2 \mathrm{~A}$ deubiquitination during the cell cycle. Ubp-M gets rapidly dephosphorylated during a shift from metaphase to anaphase $[53,54]$.

\section{Post-Translational Modifications of UCH-L1 Involved in Neurodegenerative Diseases}

UCH-L1, a ubiquitin $C$-terminal hydrolase involved in Parkinson's disease and other neurodegenerative disorders (reviewed in [55]), is highly expressed in neurons but its substrates and function have not yet been defined. UCH-L1 is $O$-glycosylated in the nerve terminals, although this modification has not been shown to have any effect on its function [56]. Moreover, UCH-L1 undergoes monoubiquitination at multiple lysines within close proximity to its active site. This PTM appears to control the enzymatic function of UCH-L1 since monoubiquitination impairs its binding to ubiquitin and an ability to increase the monoubiquitin pool in cells, but it has no effect on its localization (Fig. 1b). Importantly, UCH-L1 is able to regulate its own ubiquitination status through auto-deubiquitination, therefore controlling its catalytic capabilities in an autoregulatory feedback loop [57].

\section{Ubiquitination of USP6 in the Context of Protein- Protein Interaction}

USP6 (TRE17) is a ubiquitin-specific protease implicated in human neoplasia with unidentified targets for its DUB activity [58]. It has been shown to be mono- and polyubiquitinated, and mono-ubiquitination of USP6 depends on its association with calcium $\left(\mathrm{Ca}^{2+}\right)$-binding protein calmodulin (CaM). USP6 can promote its own deubiquitination, suggesting a possible mode of auto-regulation, but the physiological relevance of this modification, including the effect on its catalytic activity, remains to be uncovered [59].

\section{USP7-A Deubiquitinase Involved in Tumor Development is Phosphorylated and Ubiquitinated}

USP7 (Herpes-associated USP; HAUSP), a DUB described predominantly for its role in cancer biology, is involved in processes such as transcriptional regulation, DNA replication, apoptosis, and possibly in endosomal organization ([60], reviewed in [61, 62]). It interacts with p53, Hdm2 and Hdmx, and its deubiquitinating function towards these proteins protects cells from apoptosis [63, 64]. PTMs documented for USP7 include phosphorylation on $\mathrm{Ser}^{18}$ and $\mathrm{Ser}^{963}$, and ubiquitination on $\mathrm{Lys}^{869}$, although any relation of these modifications to its activity has not been demonstrated so far $[65,66]$. Ser ${ }^{18}$ is likely to be a target for casein kinase 2 (CK2)-mediated phosphorylation, especially since CK2 co-immunoprecipitates with USP7, suggesting their possible interaction [66]. Both phosphorylation sites of USP7 are located near its protein-protein interaction domains, similarly to the ones of CYLD [34]. It is therefore plausible that this modification might have an effect on USP7 substrates or possibly other protein interactions. Interestingly, the ubiquitination site of USP7 is placed close to the region where it was reported to interact with ICP0, a viral E3 ubiquitin ligase [67], supporting the previous finding that ICP0 targets USP7 for ubiquitination [68].

\section{Role of Phosphorylation Events in the Activity and Stability of USP8}

USP8 (UBPY) plays a role in endosomal sorting by deubiquitinating ligand-activated epidermal growth factor (EGFR) on early endosomes [69]. A mass spectrometrybased analysis of the phosphoproteome identified USP8 as an interactor of $14-3-3 \varepsilon$ during anaphase, and two independent studies mapped the phosphorylation site to $\operatorname{Ser}^{680}$ [70, 71]. This site has been then demonstrated to be critical for the subcellular localization of USP8, and while the wildtype USP8 localizes primarily to the cytosol, the majority of USP8 was found in the nucleus if the Ser ${ }^{680}$ was mutated to alanine [70, 71], but this finding was not supported by another study [72]. Furthermore, the catalytic activity of USP8 is inhibited by phosphorylation on $\mathrm{Ser}^{680}$, based on the fact that the S680A mutant of USP8 exhibites enhanced DUB activity toward polyubiquitin chains and EGFR. This phosphorylation-mediated regulation of USP8 is present during the interphase, while during the $\mathrm{M}$ phase USP8 is dephosphorylated [72]. Another study found USP8 to be a substrate for the EGF-activated Src-family tyrosine kinases although its biological significance is not yet understood and the phosphorylation sites mediated by these kinases have not been mapped thus far [73]. USP8 is also phosphorylated by Akt on $\mathrm{Thr}^{907}$, which contributes to its stability [74, 75].

\section{Translocation and Stabilization of USP10 is Mediated by Phosphorylation}

USP10 has been recently described as a DUB targeting p53 for polyubiquitin chain cleavage [76]. As mentioned earlier, USP7 is a DUB that deubiquitinates p53 and its E3 
ligase Hdm2 [63], but in contrast to USP7, USP10 has been only found to interact with and deubiquitinate $\mathrm{p} 53$, and it is predominantly localized in the cytoplasm in unstressed cells, while USP7 is mainly a nuclear protein [76]. Therefore, while USP7 targets p53 in the nucleus, USP10 deubiquitinates cytoplasmic p53 and upon genotoxic stress it translocates to the nucleus to activate p53. ATM phosphorylates USP10 on $\mathrm{Thr}^{42}$ and $\mathrm{Ser}^{337}$, and this event is required for the stabilization of USP10 and its translocation into nucleus after DNA damage. The alanine mutation of the $\mathrm{Thr}^{42} / \mathrm{Ser}^{337}$ has not been shown to interfere with the capability of USP10 to deubiquitinate p53, but it impedes its nucleolar translocation and stabilization, which in effect suppresses USP10-mediated activation of p53 in response to DNA damage [76].

\section{Various PTMs of USP25 and their Effect on its Catalytic Activity}

The physiological role of USP25, a member of the USP family [77] remains to be explored. This USP contains a ubiquitin-associated domain (UBA) as well as two ubiquitin binding-domains (UBDs, [78]), and its muscular isoform interacts with three sarcomeric proteins, having a stabilizing effect on one of them, myosin binding protein C1 (MyBPC1; [79]). Recently, the tyrosine kinase SYK has been found to phosphorylate USP25, predictably on the $\mathrm{Tyr}^{740}$ residue. The protease activity of USP25 is not affected by SYK-mediated phosphorylation, but it decreases its protein levels, although not due to its increased proteasomal degradation [80]. USP25 is also modified by SUMO-1 and SUMO-2/3, among which the latter PTM has been shown to be more predominant. Sumoylation occurs on Lys ${ }^{99}$ and Lys ${ }^{141}$, which are located within the ubiquitin-interacting motif (UIM), required for the protease activity of USP25. USP25 sumoylation indeed inhibits the catalytic activity of USP 25 imposed by its reduced binding to polyubiquitin chains [81]. Moreover, ubiquitination of muscular isoforms of USP25 has also been detected, and similarly to sumoylation it affected Lys ${ }^{99}$. Mutation of this residue negatively regulates USP25-mediated stabilization of MyBPC1 and a mutually exclusive modification on Lys ${ }^{99}$ - sumoylation and ubiquitination-might have opposite effects on the enzyme isopeptidase activity. Importantly, USP25 is able to auto-deubiquitinate itself possibly representing a mechanism of auto-regulation [78].

\section{ATM/IR-Dependent Phosphorylation of USP28}

A deubiquitinase USP28 binds to the $\mathrm{SCF}^{\mathrm{Fbw} 7}$ ubiquitin E3 ligase, stabilizing Myc, and therefore promoting cell proliferation [82]. Moreover, USP28 binds checkpoint proteins 53BP1, Claspin, and Mdc1 [83]. In response to IR, USP28 becomes phosphorylated on $\mathrm{Ser}^{67}$ and $\mathrm{Ser}^{714}$ in an ATM-dependent manner [83]. This modification is likely to regulate the complex-formation with the DNA checkpoint proteins, supported by the fact that cell exposure to irradiation induces Myc dissociation from USP28 [82].

\section{Phosphorylation of USP44 during Mitosis}

USP44, a predominantly nuclear DUB and an important regulator of the spindle checkpoint, undergoes phosphorylation during mitosis [84]. This step may activate USP44 specifically for the checkpoint arrest, regulated for instance by mitotic cyclin-dependent kinases or spindle checkpoint kinases [85]. Moreover, USP44 is a documented target for Lys $^{48}$ - and Lys ${ }^{63}$-linked polyubiquitination, but the effect of these modifications is not yet understood [84].

\section{PTMs on DUBs Identified by Global Proteomics Studies}

In addition to the biochemically-characterized examples of PTMs, several high-throughput studies aimed at mapping the phosphoproteome, ubiquitinome, and acetylome yielded information on additional post-translationally modified residues in DUBs (several such studies are summarized in Table 2, [65, 86-114]). Strikingly, large-scale phosphoproteomics studies have found 37 out of 55 USPs to be phosphorylated in vivo (reviewed in [115]). Global phosphoproteome analyses targeted to a particular kinase might be of special value, placing a phosphorylated DUB within a biological context. For instance, Matsuoka et al. [90] detected various DUBs as kinase substrates of ATM (ataxia telangiectasia mutated) and ATR (ATM and Rad3-related) in response to the DNA damage, which include USP1, UCHL3, USP19, USP24, USP28, and USP34, although the relevance of ATM/ATR-mediated phosphorylation of these enzymes is presently unclear [90]. Furthermore, proteomic studies such as [8] provide information on novel proteinprotein interactions, including association with kinases, methyl transferases, and other proteins that might posttranslationally modify DUBs.

All this indicates that the number of the PTMs affecting DUBs must be extensive, providing a great scope for future studies exploring roles of these already discovered modifications. Location of the modifiable residues within various DUB domains might give an initial clue on the mechanistic effect of PTMs on DUB function. For instance, different outcomes are to be expected for modifications occurring within the ubiquitin-binding domain, components of the catalytic site, or protein-protein interaction domains. 


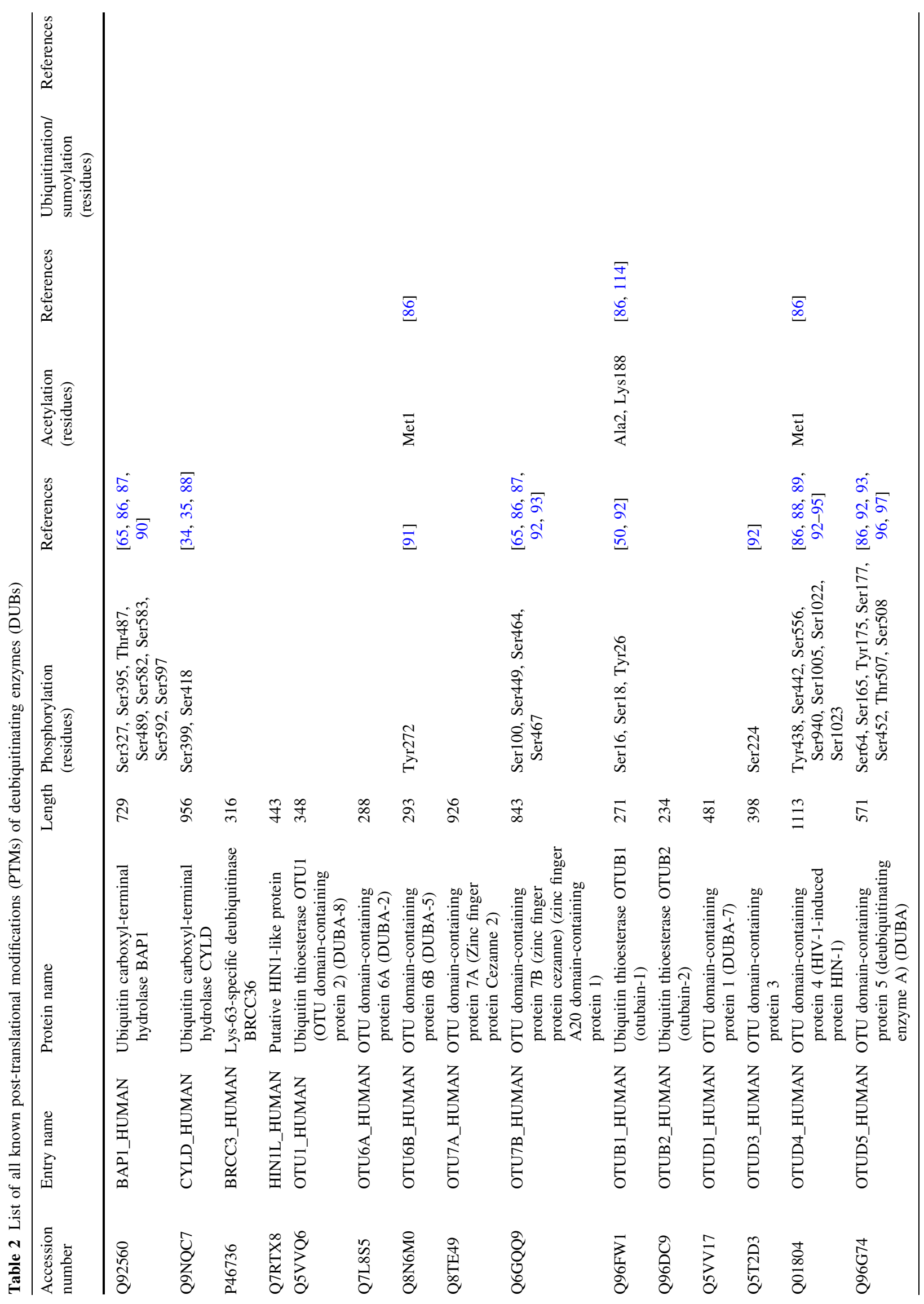




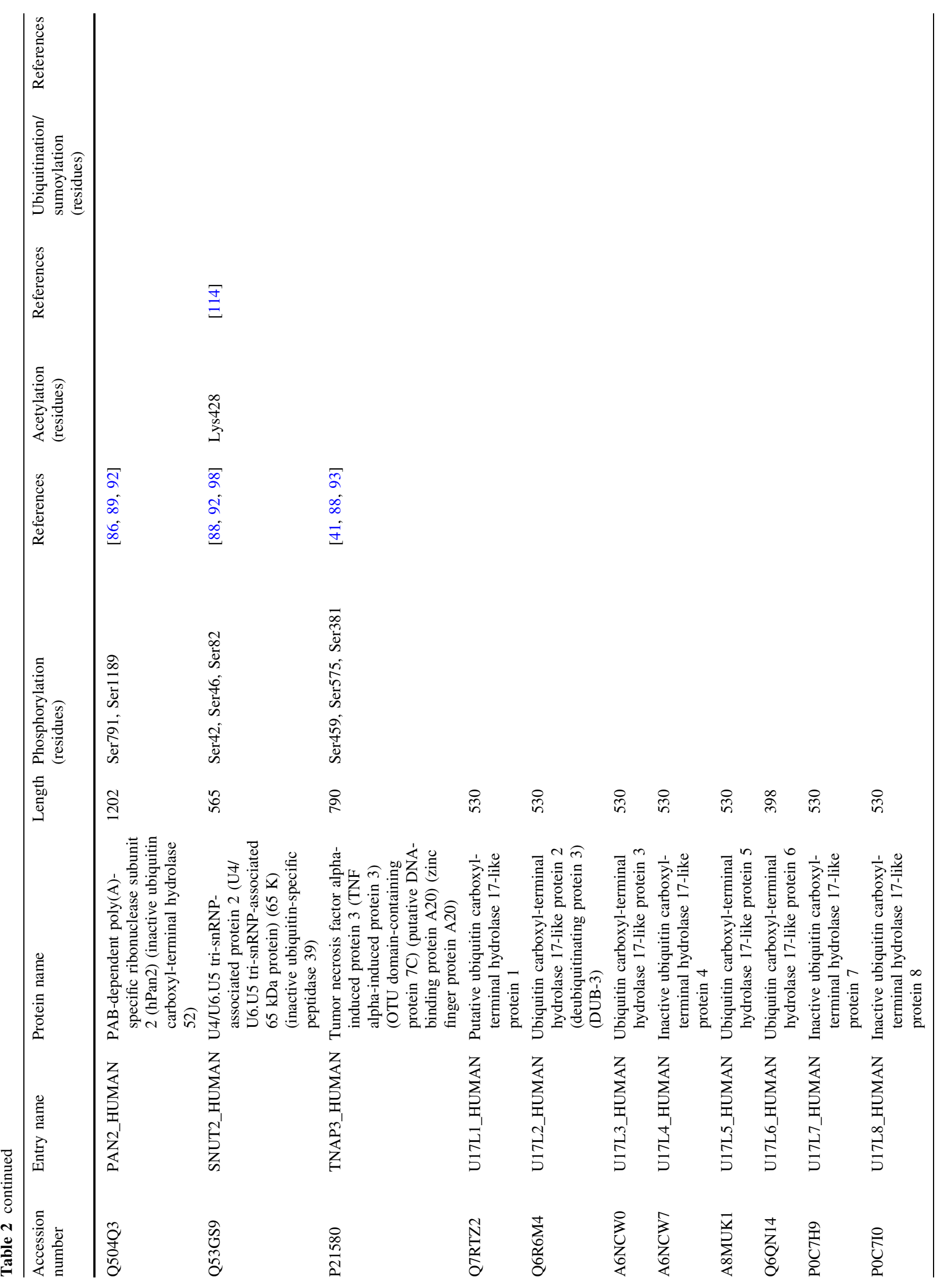




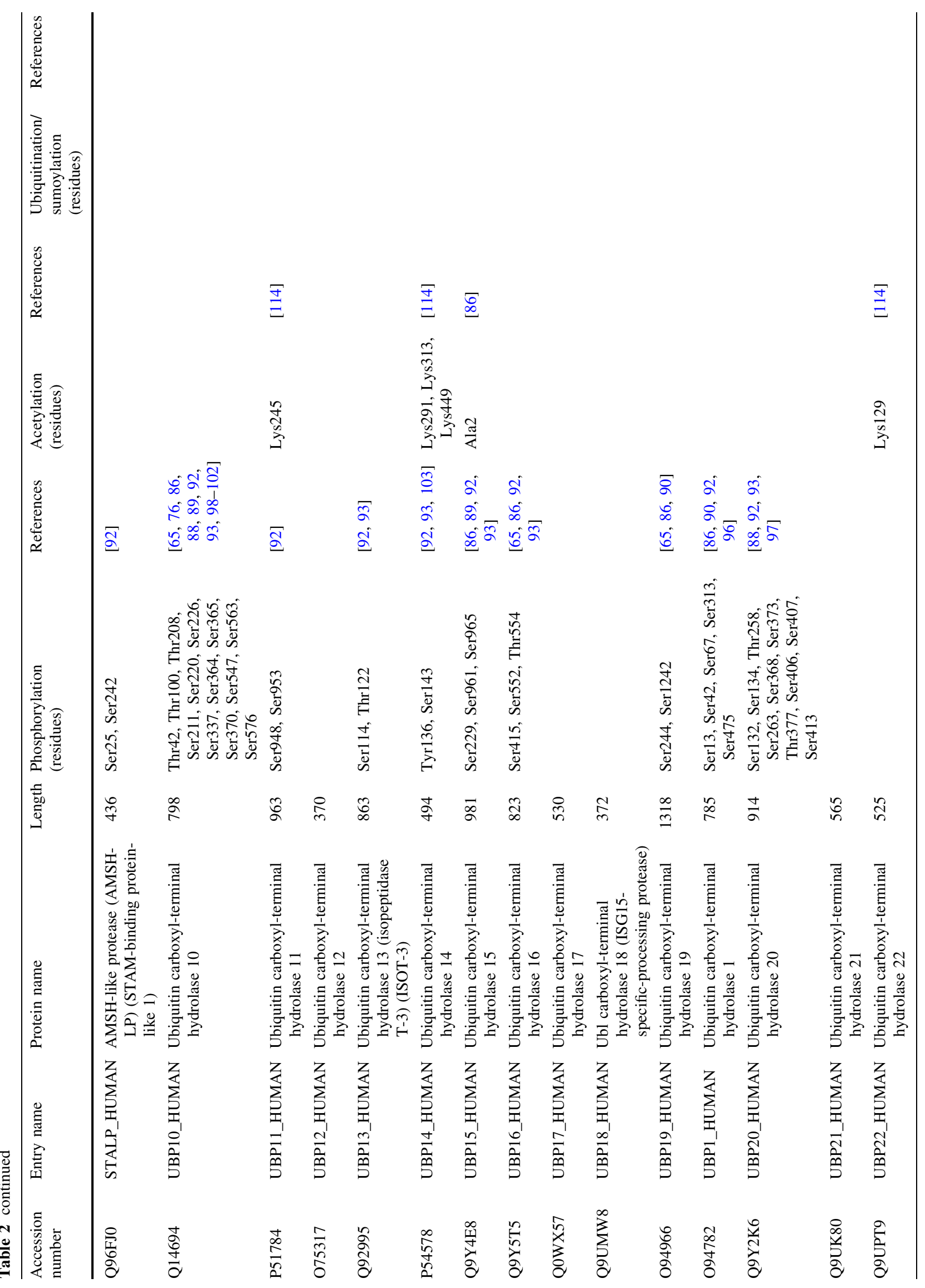




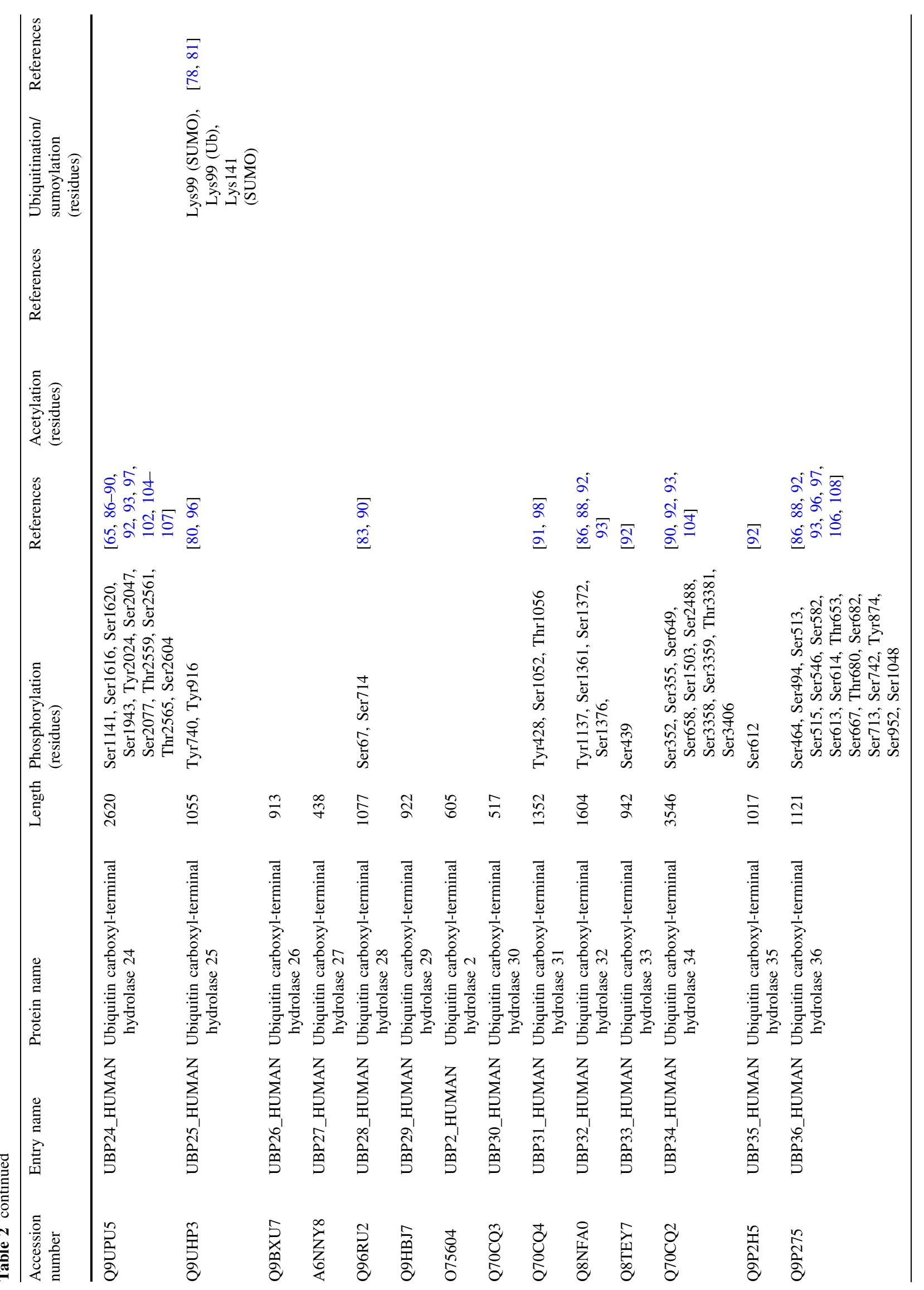




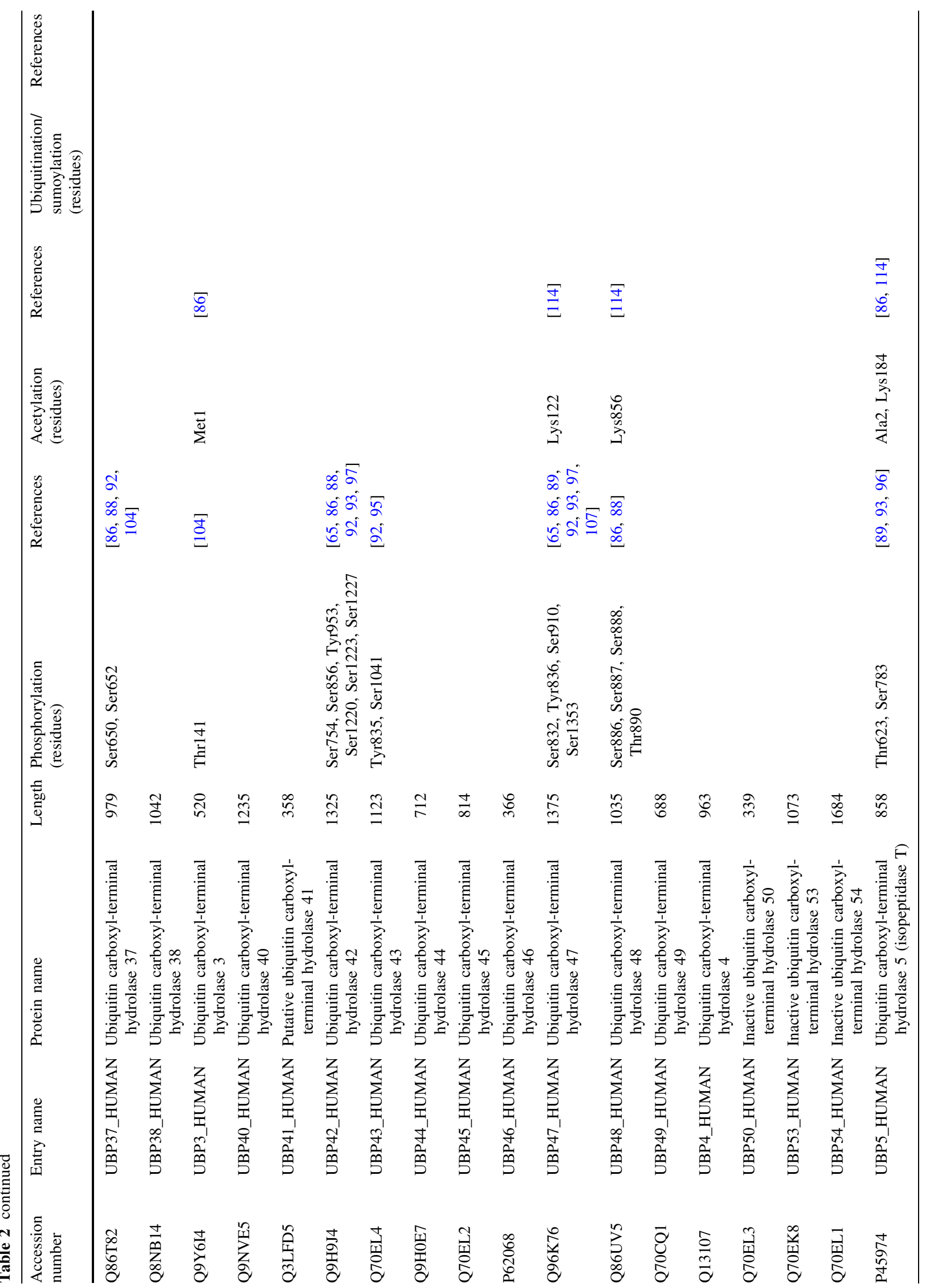




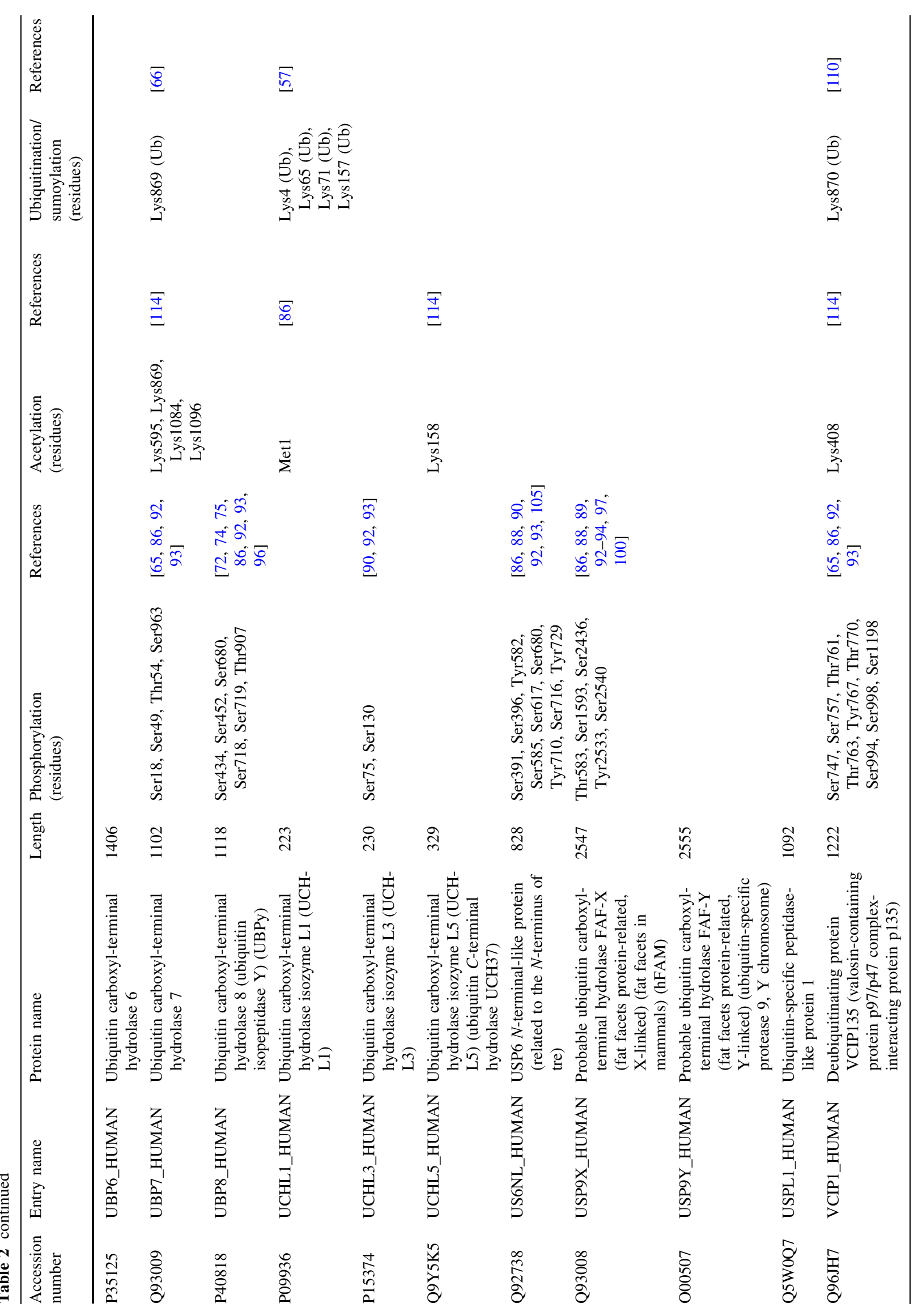




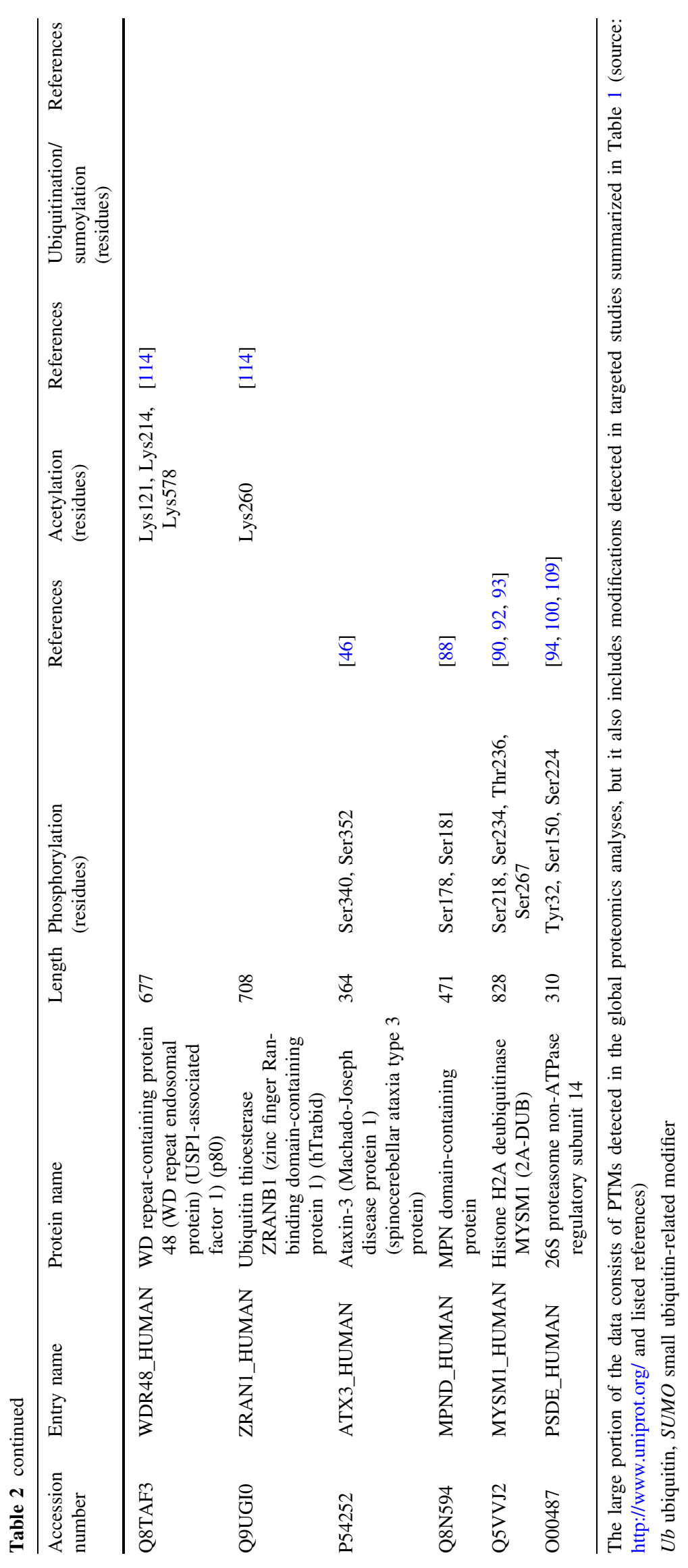




\section{Multi-PTM Crosstalk}

Although there are multiple examples of post-translationally modified DUBs, the biochemical data is too scarce to draw any general conclusions, especially in relation to PTM-mediated regulation of the catalytic activity of DUBs. Future studies are likely to reveal trans-regulatory mechanisms of PTMs in the control of DUB catalytic activity and function. Such complex crosstalks between pathways have been recognized for many proteins, perhaps best described for kinases and histones. For instance, in some cases priming phosphorylation events are necessary to enable subsequent phosphorylation, sumoylation, or ubiquitination, while methylation or ubiquitination of certain residues in histones might be a prerequisite for their acetylation (reviewed in [116]). So far, no example of a similar mechanism has been discovered for DUBs, but they are anticipated. In particular, an occurrence of a phosphodegron, or a priming phosphorylation event necessary for recognition by an E3 ubiquitin ligase, leading to ubiquitination and proteasomal degradation, should be carefully examined for DUBs down-regulated by phosphorylation events. For instance, phosphorylation of USP25 [80] might trigger subsequent $\mathrm{Lys}^{48}$-polyubiquitination resulting in proteasomal degradation. On the other hand, phosphorylation-driven negative regulation of ubiquitination might also be common. For example, it would be interesting to investigate this mechanism for USP8, since phosphorylation of $\mathrm{Thr}^{907}$ leads to accumulation of this protein [74, 75]. Another attractive aspect of post-translational events is a direct competition for a modifiable residue, such as for USP25, where Lys ${ }^{99}$ has been shown to be both ubiquitinated and sumoylated, with a potentially opposite functional outcome $[78,81]$.

\section{Auto-Regulatory Mechanisms Keep DUBs in Check}

Internal adaptive mechanisms controlling kinase enzymatic activity and therefore cell homeostasis have been known for a long time (reviewed in $[117,118]$ ), but they have also been described for E3 ubiquitin ligases (e.g., Smurf2 [119]) and acetyltransferases (e.g., Rtt109 [120]). Since attachment of ubiquitin or ubiquitin-like molecules to protein substrates has been recognized as a multi-purpose regulatory modification, self-deubiquitination represents an attractive means of auto-regulation, whether it concerns control over lifespan, localization, or catalytic activity of DUBs. Indeed, this principle has been proposed for UCHL1 [57], USP6 [59], and USP25 [78]. Monoubiquitination is particularly interesting since it impairs deubiquitinating properties of UCH-L1, while USP25 catalytic activity is most likely induced by this PTM $[57,78]$. These studies indicate that auto-deubiquitination might contribute to both, inhibition and activation of the DUB function.

Further knowledge on how DUB function is regulated by PTMs may provide novel insights into their biology. Moreover, since many DUBs are implicated in cancer, inflammation, microbial disease, and neurodegeneration, novel insights into PTM-mediated regulation of DUBs might provide opportunities for combining inhibitors of DUBs and enzymes responsible for regulatory PTMs (e.g., kinase or phosphatase inhibitors) as more efficient entry points for pharmacological intervention strategies.

Acknowledgements B.M.K. is supported by the NIHR Biomedical Research Centre, Oxford, UK, and an Action Medical Research Grant (Charity No. 208701 and SC039284). M.J.E. is supported by the USDA NIFA grant 2009-34609-20222. Approved for publication as Journal Article No. J-12003 of the Mississippi Agricultural and Forestry Experiment Station, Mississippi State University.

Open Access This article is distributed under the terms of the Creative Commons Attribution Noncommercial License which permits any noncommercial use, distribution, and reproduction in any medium, provided the original author(s) and source are credited.

\section{References}

1. Nijman, S. M., Luna-Vargas, M. P., Velds, A., Brummelkamp, T. R., Dirac, A. M., Sixma, T. K., et al. (2005). A genomic and functional inventory of deubiquitinating enzymes. Cell, 123, 773-786.

2. Wing, S. S. (2003). Deubiquitinating enzymes-the importance of driving in reverse along the ubiquitin-proteasome pathway. International Journal of Biochemistry and Cell Biology, 35, 590-605.

3. Piotrowski, J., Beal, R., Hoffman, L., Wilkinson, K. D., Cohen, R. E., \& Pickart, C. M. (1997). Inhibition of the 26 S proteasome by polyubiquitin chains synthesized to have defined lengths. Journal of Biological Chemistry, 272, 23712-23721.

4. Raasi, S., Varadan, R., Fushman, D., \& Pickart, C. M. (2005). Diverse polyubiquitin interaction properties of ubiquitin-associated domains. Nature Structural and Molecular Biology, 12, 708-714.

5. Wilkinson, K. D., Tashayev, V. L., O'Connor, L. B., Larsen, C. N., Kasperek, E., \& Pickart, C. M. (1995). Metabolism of the polyubiquitin degradation signal: Structure, mechanism, and role of isopeptidase T. Biochemistry, 34, 14535-14546.

6. D'Andrea, A., \& Pellman, D. (1998). Deubiquitinating enzymes: A new class of biological regulators. Critical Reviews in Biochemistry and Molecular Biology, 33, 337-352.

7. Komander, D., Clague, M. J., \& Urbe, S. (2009). Breaking the chains: Structure and function of the deubiquitinases. Nature Reviews Molecular Cell Biology, 10, 550-563.

8. Sowa, M. E., Bennett, E. J., Gygi, S. P., \& Harper, J. W. (2009). Defining the human deubiquitinating enzyme interaction landscape. Cell, 138, 389-403.

9. Singhal, S., Taylor, M. C., \& Baker, R. T. (2008). Deubiquitylating enzymes and disease. Biomedical Central Biochemistry, 9(Suppl 1), S3.

10. Reyes-Turcu, F. E., Ventii, K. H., \& Wilkinson, K. D. (2009). Regulation and cellular roles of ubiquitin-specific deubiquitinating enzymes. Annual Review of Biochemistry, 78, 363-397. 
11. Dang, L. C., Melandri, F. D., \& Stein, R. L. (1998). Kinetic and mechanistic studies on the hydrolysis of ubiquitin $C$-terminal 7-amido-4-methylcoumarin by deubiquitinating enzymes. Biochemistry, 37, 1868-1879.

12. Edelmann, M. J., Iphofer, A., Akutsu, M., Altun, M., di Gleria, K., Kramer, H. B., et al. (2009). Structural basis and specificity of human otubain 1-mediated deubiquitination. Biochemical Journal, 418, 379-390.

13. Hu, M., Li, P., Li, M., Li, W., Yao, T., Wu, J. W., et al. (2002). Crystal structure of a UBP-family deubiquitinating enzyme in isolation and in complex with ubiquitin aldehyde. Cell, 111, 1041-1054.

14. Hu, M., Li, P., Song, L., Jeffrey, P. D., Chenova, T. A., Wilkinson, K. D., et al. (2005). Structure and mechanisms of the proteasome-associated deubiquitinating enzyme USP14. EMBO Journal, 24, 3747-3756.

15. Johnston, S. C., Larsen, C. N., Cook, W. J., Wilkinson, K. D., \& Hill, C. P. (1997). Crystal structure of a deubiquitinating enzyme (human UCH-L3) at 1.8 A resolution. EMBO Journal, 16, 3787-3796.

16. Johnston, S. C., Riddle, S. M., Cohen, R. E., \& Hill, C. P. (1999). Structural basis for the specificity of ubiquitin $C$-terminal hydrolases. EMBO Journal, 18, 3877-3887.

17. Lin, S. C., Chung, J. Y., Lamothe, B., Rajashankar, K., Lu, M., Lo, Y. C., et al. (2008). Molecular basis for the unique deubiquitinating activity of the NF-kappaB inhibitor A20. Journal of Molecular Biology, 376, 526-540.

18. Misaghi, S., Galardy, P. J., Meester, W. J., Ovaa, H., Ploegh, H. L., \& Gaudet, R. (2005). Structure of the ubiquitin hydrolase UCH-L3 complexed with a suicide substrate. Journal of Biological Chemistry, 280, 1512-1520.

19. Reyes-Turcu, F. E., Horton, J. R., Mullally, J. E., Heroux, A., Cheng, X., \& Wilkinson, K. D. (2006). The ubiquitin binding domain $\mathrm{ZnF}$ UBP recognizes the $C$-terminal diglycine motif of unanchored ubiquitin. Cell, 124, 1197-1208.

20. Ventii, K. H., \& Wilkinson, K. D. (2008). Protein partners of deubiquitinating enzymes. Biochemical Journal, 414, 161-175.

21. Borodovsky, A., Kessler, B. M., Casagrande, R., Overkleeft, H. S., Wilkinson, K. D., \& Ploegh, H. L. (2001). A novel active site-directed probe specific for deubiquitylating enzymes reveals proteasome association of USP14. EMBO Journal, 20, 5187-5196.

22. Verma, R., Aravind, L., Oania, R., McDonald, W. H., Yates, J. R., 3rd, Koonin, E. V., et al. (2002). Role of Rpn11 metalloprotease in deubiquitination and degradation by the $26 \mathrm{~S}$ proteasome. Science, 298, 611-615.

23. McCullough, J., Row, P. E., Lorenzo, O., Doherty, M., Beynon, R., Clague, M. J., et al. (2006). Activation of the endosomeassociated ubiquitin isopeptidase AMSH by STAM, a component of the multivesicular body-sorting machinery. Current Biology, 16, 160-165.

24. Yao, T., Song, L., Jin, J., Cai, Y., Takahashi, H., Swanson, S. K., et al. (2008). Distinct modes of regulation of the Uch37 deubiquitinating enzyme in the proteasome and in the Ino80 chromatin-remodeling complex. Molecular Cell, 31, 909-917.

25. Huang, T. T., Nijman, S. M., Mirchandani, K. D., Galardy, P. J., Cohn, M. A., Haas, W., et al. (2006). Regulation of monoubiquitinated PCNA by DUB autocleavage. Nature Cell Biology, 8, 339-347.

26. Kovalenko, A., Chable-Bessia, C., Cantarella, G., Israel, A., Wallach, D., \& Courtois, G. (2003). The tumour suppressor CYLD negatively regulates NF-kappaB signalling by deubiquitination. Nature, 424, 801-805.

27. Brummelkamp, T. R., Nijman, S. M., Dirac, A. M., \& Bernards, R. (2003). Loss of the cylindromatosis tumour suppressor inhibits apoptosis by activating NF-kappaB. Nature, 424, 797-801.
28. Trompouki, E., Hatzivassiliou, E., Tsichritzis, T., Farmer, H., Ashworth, A., \& Mosialos, G. (2003). CYLD is a deubiquitinating enzyme that negatively regulates NF-kappaB activation by TNFR family members. Nature, 424, 793-796.

29. Sun, S. C. (2010). CYLD: A tumor suppressor deubiquitinase regulating NF-kappaB activation and diverse biological processes. Cell Death and Differentiation, 17, 25-34.

30. Lim, J. H., Jono, H., Koga, T., Woo, C. H., Ishinaga, H., Bourne, P., et al. (2007). Tumor suppressor CYLD acts as a negative regulator for non-typeable Haemophilus influenza-induced inflammation in the middle ear and lung of mice. PLoS One, 2, e1032.

31. Lim, J. H., Stirling, B., Derry, J., Koga, T., Jono, H., Woo, C. H., et al. (2007). Tumor suppressor CYLD regulates acute lung injury in lethal Streptococcus pneumoniae infections. Immunity, 27, 349-360.

32. Sakai, A., Koga, T., Lim, J. H., Jono, H., Harada, K., Szymanski, E., et al. (2007). The bacterium, nontypeable Haemophilus influenzae, enhances host antiviral response by inducing Toll-like receptor 7 expression: Evidence for negative regulation of host anti-viral response by CYLD. FEBS Journal, 274, 3655-3668.

33. Lim, J. H., Ha, U. H., Woo, C. H., Xu, H., \& Li, J. D. (2008). CYLD is a crucial negative regulator of innate immune response in Escherichia coli pneumonia. Cellular Microbiology, 10, 2247-2256.

34. Reiley, W., Zhang, M., Wu, X., Granger, E., \& Sun, S. C. (2005). Regulation of the deubiquitinating enzyme CYLD by IkappaB kinase gamma-dependent phosphorylation. Molecular and Cellular Biology, 25, 3886-3895.

35. Hutti, J. E., Shen, R. R., Abbott, D. W., Zhou, A. Y., Sprott, K. M., Asara, J. M., et al. (2009). Phosphorylation of the tumor suppressor CYLD by the breast cancer oncogene IKKepsilon promotes cell transformation. Molecular Cell, 34, 461-472.

36. Lee, E. G., Boone, D. L., Chai, S., Libby, S. L., Chien, M., Lodolce, J. P., et al. (2000). Failure to regulate TNF-induced NF-kappaB and cell death responses in A20-deficient mice. Science, 289, 2350-2354.

37. Wertz, I. E., O’Rourke, K. M., Zhou, H., Eby, M., Aravind, L., Seshagiri, S., et al. (2004). De-ubiquitination and ubiquitin ligase domains of A20 downregulate NF-kappaB signalling. Nature, 430, 694-699.

38. Boone, D. L., Turer, E. E., Lee, E. G., Ahmad, R. C., Wheeler, M. T., Tsui, C., et al. (2004). The ubiquitin-modifying enzyme A20 is required for termination of Toll-like receptor responses. Nature Immunology, 5, 1052-1060.

39. Balakirev, M. Y., \& Wilkinson, K. D. (2008). OTU takes the chains OUT. Nature Chemical Biology, 4, 227-228.

40. Heyninck, K., \& Beyaert, R. (2005). A20 inhibits NF-kappaB activation by dual ubiquitin-editing functions. Trends in Biochemical Sciences, 30, 1-4.

41. Hutti, J. E., Turk, B. E., Asara, J. M., Ma, A., Cantley, L. C., \& Abbott, D. W. (2007). IkappaB kinase beta phosphorylates the K63 deubiquitinase A20 to cause feedback inhibition of the NFkappaB pathway. Molecular and Cellular Biology, 27, 7451-7461.

42. Nicastro, G., Masino, L., Esposito, V., Menon, R. P., De Simone, A., Fraternali, F., et al. (2009). Josephin domain of ataxin-3 contains two distinct ubiquitin-binding sites. Biopolymers, 91, 1203-1214.

43. Winborn, B. J., Travis, S. M., Todi, S. V., Scaglione, K. M., Xu, P., Williams, A. J., et al. (2008). The deubiquitinating enzyme ataxin-3, a polyglutamine disease protein, edits Lys63 linkages in mixed linkage ubiquitin chains. Journal of Biological Chemistry, 283, 26436-26443.

44. Todi, S. V., Laco, M. N., Winborn, B. J., Travis, S. M., Wen, H. M., \& Paulson, H. L. (2007). Cellular turnover of the 
polyglutamine disease protein ataxin-3 is regulated by its catalytic activity. Journal of Biological Chemistry, 282, 29348-29358.

45. Todi, S. V., Winborn, B. J., Scaglione, K. M., Blount, J. R., Travis, S. M., \& Paulson, H. L. (2009). Ubiquitination directly enhances activity of the deubiquitinating enzyme ataxin-3. EMBO Journal, 28, 372-382.

46. Mueller, T., Breuer, P., Schmitt, I., Walter, J., Evert, B. O., \& Wullner, U. (2009). CK2-dependent phosphorylation determines cellular localization and stability of ataxin-3. Human Molecular Genetics, 18, 3334-3343.

47. Wang, T., Yin, L., Cooper, E. M., Lai, M. Y., Dickey, S., Pickart, C. M., et al. (2009). Evidence for bidentate substrate binding as the basis for the K48 linkage specificity of otubain 1 . Journal of Molecular Biology, 386, 1011-1023.

48. Soares, L., Seroogy, C., Skrenta, H., Anandasabapathy, N., Lovelace, P., Chung, C. D., et al. (2004). Two isoforms of otubain 1 regulate $\mathrm{T}$ cell anergy via GRAIL. Nature Immunology, 5, 45-54.

49. Lin, J. T., Lineberry, N. B., Kattah, M. G., Su, L. L., Utz, P. J., Fathman, C. G., et al. (2009). Naive CD4 t cell proliferation is controlled by mammalian target of rapamycin regulation of GRAIL expression. Journal of Immunology, 182, 5919-5928.

50. Edelmann, M. J., Kramer, H. B., Altun, M., \& Kessler, B. M. (2010). Post-translational modification of the deubiquitinating enzyme otubain 1 modulates active RhoA levels and susceptibility to Yersinia invasion. FEBS Journal, 277, 2515-2530.

51. Nakada, S., Tai, I., Panier, S., Al-Hakim, A., Iemura, S., Juang, Y. C., et al. (2010). Non-canonical inhibition of DNA damagedependent ubiquitination by OTUB1. Nature, 466, 941-946.

52. Rose, A., \& Schlieker, C. (2010). DNA repair: Blocking ubiquitin transfer. Nature, 466, 929-930.

53. Cai, S. Y., Babbitt, R. W., \& Marchesi, V. T. (1999). A mutant deubiquitinating enzyme (Ubp-M) associates with mitotic chromosomes and blocks cell division. Proceedings of the National Academy of Sciences USA, 96, 2828-2833.

54. Joo, H. Y., Zhai, L., Yang, C., Nie, S., Erdjument-Bromage, H., Tempst, P., et al. (2007). Regulation of cell cycle progression and gene expression by H2A deubiquitination. Nature, 449, $1068-1072$.

55. Day, I. N., \& Thompson, R. J. (2010). UCHL1 (PGP 9.5): Neuronal biomarker and ubiquitin system protein. Progress in Neurobiology, 90, 327-362.

56. Cole, R. N., \& Hart, G. W. (2001). Cytosolic $O$-glycosylation is abundant in nerve terminals. Journal of Neurochemistry, 79, 1080-1089.

57. Meray, R. K., \& Lansbury, P. T., Jr. (2007). Reversible monoubiquitination regulates the Parkinson disease-associated ubiquitin hydrolase UCH-L1. Journal of Biological Chemistry, 282, 10567-10575.

58. Oliveira, A. M., Hsi, B. L., Weremowicz, S., Rosenberg, A. E., Dal Cin, P., Joseph, N., et al. (2004). USP6 (Tre2) fusion oncogenes in aneurysmal bone cyst. Cancer Research, 64, 1920-1923.

59. Shen, C., Ye, Y., Robertson, S. E., Lau, A. W., Mak, D. O., \& Chou, M. M. (2005). Calcium/calmodulin regulates ubiquitination of the ubiquitin-specific protease TRE17/USP6. Journal of Biological Chemistry, 280, 35967-35973.

60. Kessler, B. M., Fortunati, E., Melis, M., Pals, C. E., Clevers, H., \& Maurice, M. M. (2007). Proteome changes induced by knockdown of the deubiquitylating enzyme HAUSP/USP7. Journal of Proteome Research, 6, 4163-4172.

61. Brooks, C. L., \& Gu, W. (2004). Dynamics in the p53-Mdm2 ubiquitination pathway. Cell Cycle, 3, 895-899.

62. Lee, J. T., \& Gu, W. (2010). The multiple levels of regulation by p53 ubiquitination. Cell Death Differentiation, 17, 86-92.
63. Li, M., Chen, D., Shiloh, A., Luo, J., Nikolaev, A. Y., Qin, J., et al. (2002). Deubiquitination of p53 by HAUSP is an important pathway for p53 stabilization. Nature, 416, 648-653.

64. Meulmeester, E., Maurice, M. M., Boutell, C., Teunisse, A. F., Ovaa, H., Abraham, T. E., et al. (2005). Loss of HAUSP-mediated deubiquitination contributes to DNA damage-induced destabilization of $\mathrm{Hdmx}$ and $\mathrm{Hdm} 2$. Molecular Cell, 18 , 565-576.

65. Beausoleil, S. A., Jedrychowski, M., Schwartz, D., Elias, J. E., Villen, J., Li, J., et al. (2004). Large-scale characterization of HeLa cell nuclear phosphoproteins. Proceedings of the National Academy of Sciences USA, 101, 12130-12135.

66. Fernandez-Montalvan, A., Bouwmeester, T., Joberty, G., Mader, R., Mahnke, M., Pierrat, B., et al. (2007). Biochemical characterization of USP7 reveals post-translational modification sites and structural requirements for substrate processing and subcellular localization. FEBS Journal, 274, 4256-4270.

67. Holowaty, M. N., Sheng, Y., Nguyen, T., Arrowsmith, C., \& Frappier, L. (2003). Protein interaction domains of the ubiquitinspecific protease, USP7/HAUSP. Journal of Biological Chemistry, 278, 47753-47761.

68. Boutell, C., Canning, M., Orr, A., \& Everett, R. D. (2005). Reciprocal activities between herpes simplex virus type 1 regulatory protein ICP0, a ubiquitin E3 ligase, and ubiquitin-specific protease USP7. Journal of Virology, 79, 12342-12354.

69. Mizuno, E., Kobayashi, K., Yamamoto, A., Kitamura, N., \& Komada, M. (2006). A deubiquitinating enzyme UBPY regulates the level of protein ubiquitination on endosomes. Traffic, 7 , 1017-1031.

70. Ballif, B. A., Cao, Z., Schwartz, D., Carraway, K. L., 3rd, \& Gygi, S. P. (2006). Identification of 14-3-3 epsilon substrates from embryonic murine brain. Journal of Proteome Research, 5, 2372-2379.

71. Ballif, B. A., Villen, J., Beausoleil, S. A., Schwartz, D., \& Gygi, S. P. (2004). Phosphoproteomic analysis of the developing mouse brain. Molecular and Cellular Proteomics, 3, 1093-1101.

72. Mizuno, E., Kitamura, N., \& Komada, M. (2007). 14-3-3dependent inhibition of the deubiquitinating activity of UBPY and its cancellation in the M phase. Experimental Cell Research, 313, 3624-3634.

73. Alwan, H. A. J., \& van Leeuwen, J. E. M. (2007). UBPYmediated epidermal growth factor receptor (EGFR) de-ubiquitination promotes EGFR degradation. Journal of Biological Chemistry, 282, 1658-1669.

74. Cao, Z. W., Wu, X. L., Yen, L., Sweeney, C., \& Carraway, K. L. (2007). Neuregulin-induced ErbB3 downregulation is mediated by a protein stability cascade involving the E3 ubiquitin ligase Nrdp1. Molecular and Cellular Biology, 27, 2180-2188.

75. Cai, J. J., Crotty, T. M., Reichert, E., Carraway, K. L., Stafforini, D. M., \& Topham, M. K. (2010). Diacylglycerol Kinase delta and Protein Kinase $\mathrm{C}$ alpha Modulate Epidermal Growth Factor Receptor Abundance and Degradation through Ubiquitinspecific Protease 8. Journal of Biological Chemistry, 285, 6952-6959.

76. Yuan, J., Luo, K., Zhang, L., Cheville, J. C., \& Lou, Z. (2010). USP10 regulates p53 localization and stability by deubiquitinating p53. Cell, 140, 384-396.

77. Valero, R., Marfany, G., Gonzalez-Angulo, O., GonzalezGonzalez, G., Puelles, L., \& Gonzalez-Duarte, R. (1999). USP25, a novel gene encoding a deubiquitinating enzyme, is located in the gene-poor region 21q11.2. Genomics, 62, 395-405.

78. Denuc, A., Bosch-Comas, A., Gonzalez-Duarte, R., \& Marfany, G. (2009). The UBA-UIM domains of the USP25 regulate the enzyme ubiquitination state and modulate substrate recognition. PLoS One, 4, e5571. 
79. Bosch-Comas, A., Lindsten, K., Gonzalez-Duarte, R., Masucci, M. G., \& Marfany, G. (2006). The ubiquitin-specific protease USP25 interacts with three sarcomeric proteins. Cellular and Molecular Life Sciences, 63, 723-734.

80. Cholay, M., Reverdy, C., Benarous, R., Colland, F., \& Daviet, L. (2010). Functional interaction between the ubiquitin-specific protease 25 and the SYK tyrosine kinase. Experimental Cell Research, 316, 667-675.

81. Meulmeester, E., Kunze, M., Hsiao, H. H., Urlaub, H., \& Melchior, F. (2008). Mechanism and consequences for paralogspecific sumoylation of ubiquitin-specific protease 25. Molecular Cell, 30, 610-619.

82. Popov, N., Herold, S., Llamazares, M., Schulein, C., \& Eilers, M. (2007). Fbw7 and Usp28 regulate myc protein stability in response to DNA damage. Cell Cycle, 6, 2327-2331.

83. Zhang, D., Zaugg, K., Mak, T. W., \& Elledge, S. J. (2006). A role for the deubiquitinating enzyme USP28 in control of the DNA-damage response. Cell, 126, 529-542.

84. Suresh, B., Ramakrishna, S., Lee, H. J., Choi, J. H., Kim, J. Y., Ahn, W. S., et al. (2010). K48- and K63-linked polyubiquitination of deubiquitinating enzyme USP44. Cell Biology International, 34, 799-808.

85. Stegmeier, F., Rape, M., Draviam, V. M., Nalepa, G., Sowa, M. E., Ang, X. L. L., et al. (2007). Anaphase initiation is regulated by antagonistic ubiquitination and deubiquitination activities. Nature, 446, 876-881.

86. Gauci, S., Helbig, A. O., Slijper, M., Krijgsveld, J., Heck, A. J., \& Mohammed, S. (2009). Lys-N and trypsin cover complementary parts of the phosphoproteome in a refined SCX-based approach. Analytical Chemistry, 81, 4493-4501.

87. Cantin, G. T., Yi, W., Lu, B., Park, S. K., Xu, T., Lee, J. D., et al. (2008). Combining protein-based IMAC, peptide-based IMAC, and MudPIT for efficient phosphoproteomic analysis. Journal of Proteome Research, 7, 1346-1351.

88. Olsen, J. V., Blagoev, B., Gnad, F., Macek, B., Kumar, C., Mortensen, P., et al. (2006). Global, in vivo, and site-specific phosphorylation dynamics in signaling networks. Cell, 127, 635-648.

89. Beausoleil, S. A., Villen, J., Gerber, S. A., Rush, J., \& Gygi, S. P. (2006). A probability-based approach for high-throughput protein phosphorylation analysis and site localization. Nature Biotechnology, 24, 1285-1292.

90. Matsuoka, S., Ballif, B. A., Smogorzewska, A., McDonald, E. R., 3rd, Hurov, K. E., Luo, J., et al. (2007). ATM and ATR substrate analysis reveals extensive protein networks responsive to DNA damage. Science, 316, 1160-1166.

91. Heibeck, T. H., Ding, S. J., Opresko, L. K., Zhao, R., Schepmoes, A. A., Yang, F., et al. (2009). An extensive survey of tyrosine phosphorylation revealing new sites in human mammary epithelial cells. Journal of Proteome Research, 8, 3852-3861.

92. Dephoure, N., Zhou, C., Villen, J., Beausoleil, S. A., Bakalarski, C. E., Elledge, S. J., et al. (2008). A quantitative atlas of mitotic phosphorylation. Proceedings of the National Academy of Sciences USA, 105, 10762-10767.

93. Mayya, V., Lundgren, D. H., Hwang, S. I., Rezaul, K., Wu, L., Eng, J. K., et al. (2009). Quantitative phosphoproteomic analysis of $\mathrm{T}$ cell receptor signaling reveals system-wide modulation of protein-protein interactions. Science Signaling, 2, ra46.

94. Rush, J., Moritz, A., Lee, K. A., Guo, A., Goss, V. L., Spek, E. J., et al. (2005). Immunoaffinity profiling of tyrosine phosphorylation in cancer cells. Nature Biotechnology, 23, 94-101.

95. Wolf-Yadlin, A., Hautaniemi, S., Lauffenburger, D. A., \& White, F. M. (2007). Multiple reaction monitoring for robust quantitative proteomic analysis of cellular signaling networks.
Proceedings of the National Academy of Sciences USA, 104, $5860-5865$.

96. Yu, L. R., Zhu, Z., Chan, K. C., Issaq, H. J., Dimitrov, D. S., \& Veenstra, T. D. (2007). Improved titanium dioxide enrichment of phosphopeptides from HeLa cells and high confident phosphopeptide identification by cross-validation of MS/MS and MS/MS/MS spectra. Journal of Proteome Research, 6, 4150-4162.

97. Daub, H., Olsen, J. V., Bairlein, M., Gnad, F., Oppermann, F. S., Korner, R., et al. (2008). Kinase-selective enrichment enables quantitative phosphoproteomics of the kinome across the cell cycle. Molecular Cell, 31, 438-448.

98. Molina, H., Horn, D. M., Tang, N., Mathivanan, S., \& Pandey, A. (2007). Global proteomic profiling of phosphopeptides using electron transfer dissociation tandem mass spectrometry. Proceedings of the National Academy of Sciences USA, 104, 2199-2204.

99. Giorgianni, F., Zhao, Y., Desiderio, D. M., \& Beranova-Giorgianni, S. (2007). Toward a global characterization of the phosphoproteome in prostate cancer cells: Identification of phosphoproteins in the LNCaP cell line. Electrophoresis, 28, 2027-2034.

100. Tang, L. Y., Deng, N., Wang, L. S., Dai, J., Wang, Z. L., Jiang, X. S., et al. (2007). Quantitative phosphoproteome profiling of Wnt3a-mediated signaling network: Indicating the involvement of ribonucleoside-diphosphate reductase M2 subunit phosphorylation at residue serine 20 in canonical Wnt signal transduction. Molecular Cell Proteomics, 6, 1952-1967.

101. Han, G., Ye, M., Zhou, H., Jiang, X., Feng, S., Tian, R., et al. (2008). Large-scale phosphoproteome analysis of human liver tissue by enrichment and fractionation of phosphopeptides with strong anion exchange chromatography. Proteomics, 8 , 1346-1361.

102. Oppermann, F. S., Gnad, F., Olsen, J. V., Hornberger, R., Greff, Z., Keri, G., et al. (2009). Large-scale proteomics analysis of the human kinome. Molecular Cell Proteomics, 8, 1751-1764.

103. Carrascal, M., Ovelleiro, D., Casas, V., Gay, M., \& Abian, J. (2008). Phosphorylation analysis of primary human T lymphocytes using sequential IMAC and titanium oxide enrichment. Journal of Proteome Research, 7, 5167-5176.

104. Imami, K., Sugiyama, N., Kyono, Y., Tomita, M., \& Ishihama, Y. (2008). Automated phosphoproteome analysis for cultured cancer cells by two-dimensional nanoLC-MS using a calcined titania/C18 biphasic column. Analytical Science, 24, 161-166.

105. Brill, L. M., Salomon, A. R., Ficarro, S. B., Mukherji, M., Stettler-Gill, M., \& Peters, E. C. (2004). Robust phosphoproteomic profiling of tyrosine phosphorylation sites from human $\mathrm{T}$ cells using immobilized metal affinity chromatography and tandem mass spectrometry. Analytical Chemistry, 76, 2763-2772.

106. Wang, B., Malik, R., Nigg, E. A., \& Korner, R. (2008). Evaluation of the low-specificity protease elastase for large-scale phosphoproteome analysis. Analytical Chemistry, 80, 9526-9533.

107. Zahedi, R. P., Lewandrowski, U., Wiesner, J., Wortelkamp, S., Moebius, J., Schutz, C., et al. (2008). Phosphoproteome of resting human platelets. Journal of Proteome Research, 7, 526-534.

108. Nousiainen, M., Sillje, H. H., Sauer, G., Nigg, E. A., \& Korner, R. (2006). Phosphoproteome analysis of the human mitotic spindle. Proceedings of the National Academy of Sciences USA, 103, 5391-5396.

109. Wang, X., Chen, C. F., Baker, P. R., Chen, P. L., Kaiser, P., \& Huang, L. (2007). Mass spectrometric characterization of the affinity-purified human 26S proteasome complex. Biochemistry, $46,3553-3565$. 
110. Denis, N. J., Vasilescu, J., Lambert, J. P., Smith, J. C., \& Figeys, D. (2007). Tryptic digestion of ubiquitin standards reveals an improved strategy for identifying ubiquitinated proteins by mass spectrometry. Proteomics, 7, 868-874.

111. Mu, J. J., Wang, Y., Luo, H., Leng, M., Zhang, J., Yang, T., et al. (2007). A proteomic analysis of ataxia telangiectasia-mutated (ATM)/ATM-Rad3-related (ATR) substrates identifies the ubiquitin-proteasome system as a regulator for DNA damage checkpoints. Journal of Biological Chemistry, 282, 17330-17334.

112. Sui, S. H., Wang, J. L., Yang, B., Song, L., Zhang, J. Y., Chen, M., et al. (2008). Phosphoproteome analysis of the human Chang liver cells using SCX and a complementary mass spectrometric strategy. Proteomics, 8, 2024-2034.

113. Dephoure, N., Zhou, C., Villen, J., Beausoleil, S. A., Bakalarski, C. E., Elledge, S. J., et al. (2008). A quantitative atlas of mitotic phosphorylation. Proceedings of the National Academy of Sciences of the United States of America, 105, 10762-10767.

114. Choudhary, C., Kumar, C., Gnad, F., Nielsen, M. L., Rehman, M., Walther, T. C., et al. (2009). Lysine acetylation targets protein complexes and co-regulates major cellular functions. Science, 325, 834-840.
115. Lopez-Otin, C., \& Hunter, T. (2010). The regulatory crosstalk between kinases and proteases in cancer. Nature Reviews Cancer, 10, 278-292.

116. Hunter, T. (2007). The age of crosstalk: Phosphorylation, ubiquitination, and beyond. Molecular Cell, 28, 730-738.

117. Soderling, T. R. (1990). Protein kinases. Regulation by autoinhibitory domains. Journal of Biological Chemistry, 265, 1823-1826.

118. Pufall, M. A., \& Graves, B. J. (2002). Autoinhibitory domains: Modular effectors of cellular regulation. Annual Review of Cell and Developmental Biology, 18, 421-462.

119. Wiesner, S., Ogunjimi, A. A., Wang, H. R., Rotin, D., Sicheri, F., Wrana, J. L., et al. (2007). Autoinhibition of the HECTType ubiquitin ligase smurf 2 through its $\mathrm{c} 2$ domain. Cell, 130, 651-662.

120. Stavropoulos, P., Nagy, V., Blobel, G., \& Hoelz, A. (2008). Molecular basis for the autoregulation of the protein acetyl transferase Rtt109. Proceedings of the National Academy of Sciences USA, 105, 12236-12241.

121. Wada, K., \& Kamitani, T. (2006). UnpEL/Usp4 is ubiquitinated by Ro52 and deubiquitinated by itself. Biochemical and Biophysical Research Communications, 342, 253-258. 